\title{
Predictors of Adherence to Nutrition Recommendations in People With Non- Insulin-Dependent Diabetes Mellitus
}

\author{
SUSAN BOEHM, PhD, RN; ELIZABETH A. SCHLENK, PhD, RN; \\ MARTHA M. FUNNELL, MS, RN, CDE; HOLLY POWERS, BA; DAVID L. RONIS, PID, MA
}

The purpose of this study was to determine how the components of psychosocial adjustment to diabetes predict adherence to nutrition recommendations based on self-reported successful completion of contingency contracts. The relationships benveen the components of psychosocial adjustment and adherence to nutrition recommendations were examined in a convenience sample of patients with non-insulindependent diabetes mellitus participating in a contingency contracting intervention with nurses. Patients completed a standardized instrument, the Diabetes Care Profile, at the time they were enrolled into this randomized clinical trial. High and low levels of adherence to mutrition recommendations were identified by a median split of the number of contingency contracts completed for adherence to nutrition recommendations. Subjects who reported higher regimen adherence and a higher support ratio (received more diabetes-specific social support than desired) were significantly less likely to engage in contingency contracting for adherence to nutrition recommendations.
Effective management of non-insulin-dependent diabetes mellitus (NIDDM) requires performing many complex selfcare behaviors such as altering a nutrition regimen and engaging in regular exercise. Nutrition therapy is viewed as a cornerstone of diabetes care and often is the primary form of therapy for patients with NIDDM. The goal of nutritional intervention is to maintain near-normal glucose and lipid levels; maintain a reasonable body weight: prevent, delay, or treat nutrition-related risk factors and complications; and improve overall health.'

Adherence to a nutrition regimen requires that the patient learn specific nutrition recommendations such as altering previous nutrition patterns, implementing new nutrition behaviors, evaluating the impact of those behaviors on glycemic control, and participating in an exercise program. Selfmanagement training, which includes a variety of behavioral strategies, is viewed as an essential part of providing patients with NIDDM the appropriate level of self-care. The primary desired outcome of nutrition therapy selfmanagement training is to assist the patient in making changes in nutrition and exercise habits that will improve nutritional skills, health status, and self-care.'

Although learning new nutrition behaviors can help facilitate long-term lifestyle changes, ${ }^{2}$ adherence to a nutrition regimen is difficult and intervention often is required. Assisting patients with NIDDM in making lifelong changes has long been recognized as an important part of the practice of diabetes educators. However, patient education traditionally has focused on discussing the benefits and consequences of certain behaviors rather than a comprehensive effort to teach the skills necessary to effectively change behaviors. Applying the principles of contingency contracting provides a unique opportunity for diabetes educators and patients to work together to learn to analyze patients' behavior in relation to their environment and to choose strategies that will facilitate learning, changing, and maintaining nutrition behaviors. The Diabetes Care Profile (DCP), a standardized diabetes assessment tool, can be used to identify components

\footnotetext{
From the School of Nursing (Drs Boehm, Schlenk, and Ronis and Ms Powers) and the Michigan Diabetes Research and Training Center, School of Medicine (Ms Funnell), University of Michigan, and the Department of Veteran's Affairs (Dr Ronis), Ann Arbor, Michigan.

Correspondence to Susan Boehm, PhD, Associate Professor and Dean, Student Affairs, The University of Michigan, School of Nursing, 400 North Ingalls Building, Ann Arbor MI 48109-0482.

Reprint requests to The Diabetes Educator, 367 West Chicago Avenue. Chicago IL 60610-3025.
} 
of psychosocial adjustment that can predict adherence to nutrition recommendations during behavioral interventions such as a contingency contracting.

\section{Related Literature}

Psychosocial Adjustment The psychological and social aspects of diabetes mellitus have been the focus of several reviews. ${ }^{3.5}$ The Health Belief Model (HBM) ${ }^{0.7}$ provides a conceptual framework for predicting regimen selfmanagement. specifically adherence to nutrition recommendations in NIDDM in this study, using components of psychosocial adjustment. The HBM model postulates that persons will adhere to a medical regimen if they perceive themselves as potentially vulnerable (susceptibility), perceive the disease as severe (severity), perceive the regimen as effective (benefits), perceive few barriers in undertaking the regimen (costs), and are stimulated to adhere by internal and external cues.

Significant relationships have been reported between several HBM constructs and regimen adherence among aduits with insulin-dependent diabetes mellitus (IDDM) and NIDDM. Severity of diabetes was significantly related to adherence as measured by self-report, ${ }^{8}$ self-report in conjunctions with direct observation, ${ }^{9}$ nurse evaluation, ${ }^{10}$ and weight and blood glucose control. ${ }^{11}$ A significant relationship was found between perceived benefits of the regimen and selfreported diabetes regimen adherence. ${ }^{12}$ A significant relationship also has been shown between perceived costs or barriers and adherence and self-reported adherence, alone or in combination with self-monitoring records. ${ }^{12-16} \mathrm{~A}$ general measure of cues $^{9}$ as well as measures of diabetes-specific social support, an external cue in the HBM, ${ }^{14,16-20}$ have been significantly related to diabetes regimen adherence. A recent meta-analysis ${ }^{21}$ revealed that the health beliefs composite and its constituent, perceived barriers to adherence, were significantly related to adherence to the diabetes regimen.

In large part, the HBM provided the theoretical basis for the DCP. ${ }^{22}$ The DCP has been used to explore the relationships between components of psychosocial adjustment to diabetes and diabetes control and mortality. Perceived control problems, social impact of diabetes, regimen complexity, and barriers to adherence were significantly related to diabetes control as measured by glycosylated hemoglobin, percentage of ideal weight, and hospital admissions. ${ }^{23}$ Social impact of diabetes and regimen complexity were predictive of patient mortality in patients with NIDDM. ${ }^{24}$ No studies have used the components of psychosocial adjustment in the DCP to prospectively predict diabetes regimen selfmanagement, specifically adherence to nutrition recommendations in patients with NIDDM during a behavioral intervention of contingency contracting.

Contingency Contracting Within the context of the diabetes educator/patient relationship, contingency contracting is the process in which the diabetes educator and patient negotiate an individualized, written, and signed agreement that clearly specifies the behavior to be performed and identifies in advance the positive consequences to be given when the patient has successfully performed the behavior. ${ }^{25}$ Behavioral analysis is the foundation of behavioral interventions that focus on modifying health behavior, ${ }^{26}$ specifically adherence to nutrition recommendations in patients with NIDDM. Behavioral analysis is the process by which behavior is observed, documented, and analyzed from three perspectives: the antecedent events that precede and serve as stimuli for the behavior, small steps of behavior that make up the behavior, and consequences that follow the behav ior. ${ }^{.7}$ Techniques used to assist in behavior change during behavioral interventions are called behavioral strategies.

Behavioral analysis provides the foundation and core for the contingency contract that is developed between the patient and the diabetes educator. Behavioral analysis assumes that the patient is able to self-regulate behavior and to actively participate in the process through self-monitoring of the behavior. Through behavioral analysis of the data supplied by the patient's self-monitoring there is an opportunity to identify behavioral antecedents, the small steps that comprise the behavior, and the consequences of the behavior. Identifying these three perspectives of a given behavior can help in selecting appropriate behavioral strategies to support performing the behavior identified in the contingency contract. Using a series of contingency contracts allows the patient to gradually achieve performance of the entire regimen behavior. $^{25.28}$

Because of the complex treatment regimen for diabetes, careful and thorough assessment of the patient is essential. Determining the most effective behavioral strategies in conjunction with the patient is a challenging task for diabetes educators. Identifying components of psychosocial adjustment that may impede cr support changes in nutrition behavior can help guide the diabetes educator in designing effective contingency contracts. Using extant standardized diabetes assessment instruments such as the DCP can complement the behavioral analysis by identifying components of psychosocial adjustment predictive of patients' contingency contracting for adherence to the nutrition recommendations.

The purpose of this study was to determine if psychosocial adjustment to diabetes is predictive of adherence to nutrition recommendations for patients with NIDDM during a behavioral intervention using contingency contracting. The relationships between the components of psychosocial adjustment in the DCP and adherence to nutrition recommendations were examined in a convenience sample of patients with NIDDM participating in a behavioral intervention with nurses that used contingency contracting. The following two research questions were addressed: (a) Which of the components of psychosocial adjustment in the DCP are associated with contingency contracting for adherence to nutrition recommendations? and (b) Which of the components of psychosocial adjustment in the DCP are associated with contingency contracting for adherence to nutrition recommendations when controlling for other components of psychosocial adjustment?

\section{Methods}

Subjects The subjects were a subsample of 117 subjects with NIDDM from a larger, randomized clinical trial of contingency contracting to improve health outcomes $(\mathrm{N}=245)$. The subjects in the subsample met the following inclusion criteria: (a) had baseline and final measures of glycosylated hemoglobin (GHb), (b) were randomly assigned to one of 
the groups that wrote contingency contracts with nurses, and (c) completed at least one contingency contract in the treatment period $f$ rom baseline to final GHb.

More than half of the subjects were a recruited from a large endocrine and metabolism outpatient clinic. Ten subjects were recruited from an inpatient diabetes care unit, four from a specialty outpatient diabetes care clinic, and 36 from the community at large in response to newspaper advertisements. Subjects had been diagnosed as having diabetes for an average of 9.6 years $(S D=7.9)$. Sixty of the subjects $(51 \%)$ were taking insulin and $40(34 \%)$ were taking oral hypoglycemic medications to regulate their diabetes. The mean baseline $\mathrm{GHb}$ was $11.0 \%(\mathrm{SD}=3.7 \%)$, and almost three quarters of the subjects $(n=86)$ had baseline $\mathrm{GHb}$ levels that were above normal $(>8.0 \%)$. The mean baseline body mass index (BMI) was $30.8(\mathrm{SD}=7.3)$, and more than half of the subjects $(n=67)$ had BMI values within the range that is considered obese ( $>27.8$ for men and $>27.3$ for women). ${ }^{29}$ The treatment period from baseline to final $\mathrm{GHb}$ averaged 13.4 months $(\mathrm{SD}=6.2)$.

The subjects had a mean age of 57.5 years $(\mathrm{SD}=11.5)$, and $62 \%(n=72)$ were women. Almost three quarters of the subjects $(n=85)$ reported that they were married, and $57 \%$ $(n=67)$ had at least some college education. Sixty-three percent of the subjects $(n=74)$ reported a family/household income of $\$ 20000$ or greater, although $17 \%(n=20)$ stated that their income was less than $\$ 10000$. Fifty of the subjects $(43 \%)$ were employed, while more than half of the subjects $(n=63)$ were retired, disabled, or described themselves as homemakers.

Instruments Diabetes Care Profile (DCP) The DCP is a diabetes-specific, standardized instrument developed for the purpose of measuring "an individual's attitudes, beliefs, and behaviors concerning diabetes and the related treatment regimen." 2 " 175 This profile was developed as an individualized needs-assessment instrument to help the diabetes educator individualize instruction and counseling based on the specific needs of each patient. However, its major use to date has been as a research instrument in program evaluations and studies of diabetes populations.:- In this study the DCP was used as a research instrument and not to identify individual psychosocial adjustment problems for intervention.

The 10 components of psychosocial adjustment in the DCP are perceived diabetes control problems, social and emotional impact of the disease, perceived risk of complications, complexity of the regimen, adherence to the regimen, perceived benefits of the regimen, perceived barriers to adherence, perceived receipt of diabetes-specific social support, and support ratio. Support ratio represents the relation of received to desired diabetes-specific social support. A support ratio $<1.0$ indicates that patients perceive they get less support than they want, a support ratio that equals 1.0 indicates that received support matches desired support, and a support ratio $>1.0$ indicates that patients perceive they get more support than they want. Exemplar items from each of the components of psychosocial adjustment in the DCP are shown in Table 1.

The DCP is a self-administered, 110-item questionnaire with items scored on a 5 -point scale ( 0 to 4$)$. The means of the items in the 10 components of psychosocial adjustment in the DCP are used to compute interval level scores for each component. The DCP has content, criterion-related, and construct validity as well as internal consistency reliability. ${ }^{22}$ Content validity was enhanced by a literature review of about 250 journal articles and review of the instrument by over 800 clinicians and health educators. Evidence of criterion-related validity was shown by statistically significant correlations between the components of psychosocial adjustment and measures of glycosylated hemoglobin, percentage of ideal weight, and hospital admissions for diabetes. Construct validity of the DCP was demonstrated by the close agreement between the empirical structure of the instrument as determined by factor analysis and the planned structure, based on a variant of the HBM. Internal consistency reliability estimates for the components of psychosocial adjustment in the DCP using Cronbach's alpha ranged from .69 to .86 .

Behaviors Schedule A Behaviors Schedule was developed to classify subjects' behaviors in the contingency contracts into nominal level categories of diabetes regimen behaviors. The instrument includes criteria for classification, coding rules with key words and examples, and scoring instructions for the raters to use in assigning code numbers to the behaviors in the contingency contracts. Only adherence behaviors to nutrition recommendations were included in this study. Some examples of behaviors in the contingency contracts for adherence to nutrition recommendations are (a) I will substitute a piece of fruit for potato chips for a bedtime snack 3 times per week for 4 weeks, (b) I will keep a record of the number of times that I eat cookies for 6 weeks, and (c) I will clean and cut vegetables 2 times per week for 5 weeks and store the vegetable container near the front of the refrigerator.

Three content experts with credentials and expertise in nursing, diabetes mellitus, and behavioral analysis served on the panel to establish the content validity of the instrument. ${ }^{30-35}$ Using the content experts' ratings of relevancy, the mean content validity index of the Behaviors Schedule was .92 , which is considered high. ${ }^{31}$ Using the content experts' ratings of congruency, the average congruency percentage of the Behaviors Schedule was $98 \%$, which also is high. ${ }^{35}$

A rater was trained and evaluated prior to assisting the investigators in pilot testing the instrument on 45 subjects not in this study. ${ }^{35-38}$ Intrarater and interrater reliabilities were calculated as recommended in the literature. ${ }^{35,39-43}$ The intrarater and interrater percentage agreements and Kappa values exceeded $90 \%$ and .90 , respectively, which are considered high. Intrarater and interrater reliabilities were calculated on a random sample of $20 \%$ of the subjects in this study $(n=23)$ with the assistance of the same rater. The intrarater and interrater percentage agreements and Kappa values exceeded $90 \%$ and .997 respectively, which also are high $^{35}$ and similar to those obtained during pilot testing.

The number of contingency contracts successfully completed for adherence to nutrition recommendations was summed for each subject. Because only contingency contracts successfully completed for adherence to nutrition recommendations were included, some subjects received a 0 for this measure of adherence behaviors. The distribution of adherence behaviors to nutrition recommendations was 


\section{Table 1. Exemplar Items From the Components of Psychosocial Adjustment in the Diabetes Care Profile}

\section{Component of}

Psychosocial Adjustment

Control Problems

Social Impact

Emotional Impact

Barriers to Adherence

Benefits of Regimen

Extent of Regimen

Adherence to Regimen

Risk of Complications

Social Support

Support Ratio

\section{Item}

How often in the past year have you had changes in your blood glucose (too high or too low) because (a) you were sick or had an infection? (B) you were emotionally upset? (C) you took the wrong amount of medicine? (D) you ate too much or too little food (or skipped a meal)?

My diabetes and its treatment keep me from (a) having enough money, (b) meeting work and other responsibilities, (c) going out or traveling as much as I want, (d) being as active as I want, (e) having good relationships with people. ( $f$ ) having a schedule I like (eg, sleeping late).

Having diabetes makes my life very difficult.

I am afraid of my diabetes.

I find it hard to believe that I really have diabetes.

I feel unhappy and depressed because of my diabetes.

How often do you have trouble getting enough physical activity because (a) you are too busy? (B) it takes too much effort? (c) you don't believe it is necessary'? (d) you don't like to do it?

Following my meal plan (eating the right loods at the right times) helps me control my diabetes.

How much does glucose testing help you control your diabetes?

Has your healthcare provider recommended that you follow a meal plan or diet to (a) control your diabetes? (B) lose weight?

Have you been advised to use exchange lists (food groups) to plan your meals?

Do you take pills to regulate your diabetes (1o lower blood glucose)?

Has your healthcare professional recommended a level of exercise or physical activity for you?

How often do you (or the person who cooks your food) use the exchange lists (food groups) to plan your meals?

How often do you test for glucose at the times you have been told?

How many pills per day have you been told to take?" / How many pills do you take per day?

Taking the best possible care of diabetes will delay or prevent (a) eye problems. (b) kidney problems, (c) foot problems, (d) hardening of the arteries, (e) heart disease.

My family and friends help me a lot to (a) follow my meal plan, (b) take my medication. (c) take special care of my feet. (d) get enough physical activity, (e) test for glucose.

My family and friends (a) accept me and my diabetes, (b) discourage or upset me about my diabetes, (c) listen to me when I want to talk about my diabetes.

My family and friends help me a lot to follow my meal plan. / I want a lot of help from my family and friends in following my meal plan.

My family and friends help me a lot to get enough physical activity. I want a lot of help from my family and friends in getting enough physical activity. positively skewed and ranged from 0 to 13 (mean $=2.17$, $\mathrm{SD}=2.81$ ). High levels ( 2 to 13 contracts) and low levels ( 0 to 1 contracts) of adherence to nutrition recommendations were identified by a median split of the number of contingency contracts successfully completed for these adherence behaviors.

Procedure Following approval from the Human Subjects Review Committee, potential subjects were identified using the clinic appointment record or through responses to advertisements. The subjects were randomly assigned to contingency contracting or attention control groups. After the study was explained to the subjects and written consent obtained, baseline data were obtained and an appointment was made to begin the behavioral intervention. The baseline data consisted of $\mathrm{GHb}$, height, weight. information obtained from the DCP, and a demographic questionnaire completed by the patients.

A description of the behavioral intervention was reported previously. ${ }^{44}$ Briefly, the subjects were randomly assigned to one of four groups. The attention control group received routine care and the added attention of consistent follow-up by a clinical nurse specialist but did not write contingency contracts. The sample of subjects presented here participated in one of the following three groups that did write contingency contracts with the same nurse at each visit. The compliance group $(n=30)$ focused on behaviors directly related to the prescribed diabetes regimen, such as following the prescribed meal plan. The behavioral strategies group $(n=49)$ participated in behavioral analysis with the nurse and focused on one of four behavioral strategies (self-monitoring, stimulus control, dividing the behavior into small steps, and self-reinforcement) to support performance of the regimen behavior. The behavioral strategies with instruction group $(n=38)$ participated in behavioral analysis with the nurse, focused on behavioral strategies, and also received classes and programmed instruction about behavioral analysis and behavioral strategies.

The subjects in the latter three groups selected a specific behavior to be implemented and identified this behavior in a 


\section{Table 2. Comparison of Reliability Results for the Diabetes Care Profile}

\section{Component of Psychosocial Adjustment*}

Control Problems

Social Impact

Emotional Impact

Barriers to Adherence

Benefits of Regimen

Extent of Regimen

Adherence to Regimen

Risk of Complications

Social Support

Support Ratio

$\begin{array}{cc}\begin{array}{c}\text { Cronbach's Alpha for Two Samples } \\ \text { Original NIDDM Sample }\end{array} \\ \begin{array}{cc}\text { Sample } \\ (\mathbf{N}=213)\end{array} \\ .77 & .76 \\ .84 & .85 \\ .78 & .70 \\ .70 & .73 \\ .62 & .75 \\ .75 & .83 \\ .59 & .73 \\ .96 & .94 \\ .82 & .82 \\ .85 & .86\end{array}$

*Components of psychosocial adjustment are stated in high scoring directions (e⿳. a higher secure meins more perecived control problems).

'Original sample from 1985 Continuing Education and Development Outreach follow-up study in which subjects with NIDDM included those taking insulin and those not taking insulin (GE Hess. personal communication. April 22. 1991).

written contingency contract with a nurse. The patients were permitted to choose the behavior they were most likely to perform to increase the likelihood of experiencing success. Most patients negotiated one contingency contract per visit. The nurse provided a patient-selected reinforcer in return for self-reports of performing the specific behavior, which were periodically validated by self-monitoring records. Dates and times of subsequent appointments were negotiated by the nurses and subjects; these appointments often were made to coincide with clinic appointments, which were scheduled an average of every 3.5 months. Contingency contracts were negotiated by telephone between clinic visits by patient request. The nurses who met with the patients had a strong background in the principles of contingency contracting from having participated in similar research and/or receiving regular, ongoing supervision and instruction from the principal investigator.

Data Analysis Internal consistency reliability of the components of psychosocial adjustment in the DCP in this study was determined using Cronbach's alpha. Measures of central tendency and variability were computed on the contingency contracts successfully completed for adherence to nutrition recommendations and on the components of psychosocial adjustment in the DCP. Because of a positively skewed distribution a median split was performed on contingency contracting for adherence to nutrition recommendations and a dummy variable was created with high adherence coded 0 and low adherence coded 1 . For ease in interpreting the multivariate analyses the dummy variable was coded in the reverse direction from the original variable. Pearson and pointbiserial correlations were computed between the components of psychosocial adjustment in the DCP and the original and dichotomous measures of contingency contracting for adherence to nutrition recommendations, respectively. The relationships of the DCP predictors with contingency contracting for adherence to nutrition recommendations werc assessed by logistic regression. According to Harris s. $^{-5}$ the sample size of 94 was adequate for 10 predictors in the mullivariate analysis ( 50 plus the number of predictors). To clarify the relationships between the DCP predictors and contingency contracting for adherence to nutrition recommendations, relationships between significant DCP predictors and adherence to nutrition recommendations were tested by the chi-square test of association after reducing the scores of the components of psychosocial adjustment in the DCP into quartiles. For all analyses the alpha was set at .05.

\section{Results}

Reliability of the Diabetes Care Profile Internal consistency reliability results for the components of psychosocial adjustment in the DCP using Cronbach's alpha were obtained for 213 subjects in the larger study who completed the DCP. The alpha coefficients are shown in Table 2 with comparisons to those reported by $\mathrm{G} E$ Hess (personal communication. April 22.1991) on a similar sample of patients with NIDDM. These alpha coefficients are similar to those found by Hess with the exception of the following two: Benefits of Regimen (.62) and Adherence to Regimen (.59). With these two exceptions all alpha coefficients were equal to or greater than 70 .

Bivariate Analyses The Pearson and point-biserial correlation coefficients between the components of psychosocial adjustment in the DCP and the original and dichotomous measures of contingency contracting for adherence to nutrition recommendations, respectively, are shown in Table 3. Significant low to moderate correlations were found between contingency contracting for adherence to nutrition recommendations and regimen adherence $(P<.01)$, social support $(P<.05$ and $P<.01)$, and support ratio $(P<.01)$. High regimen adherence, high received social support, and high support ratio (received more social support than desired) were significantly associated with low contingency 
Table 3. Pearson and Point-Biserial Correlation Coefficients Between Components of Psychosocial Adjustment in the Diabetes Care Profile and Contingency Contracting for Adherence to Nutrition Recommendations

Contingency Contracting for Adherence to Nutrition Recommendations

Component of Psychosocial Adjustment*

Control Problems

Social Impact

Emotional Impact

Barriers to Adherence

Benefits of Regimen

Extent of Regimen

Adherence to Regimen

Risk of Complications

Social Support

Support Ratio n

117

114

116

110

112

117

116

117

112

110
Number of Contracts

Successfully Completed

for Adherence

$$
.00
$$

$-.02$

.13

.13

$-.05$

$-.01$

$-.32^{\ddagger}$

.06

$-.23^{s}$

$-.31 \neq$
Adherence Level'

. 01

$-.13$

$-.10$

.10

.05

$.31 \div$

.05

$.25 \dot{s}$

$.29 \ddagger$

*Components of psychosocial adjustment are stated in high scoring directions (eg. a higher score means more perceived control problems).

${ }^{\circ} 0=$ High Adherence. $l=$ Low Adherence.

${ }^{\ddagger} P<.01$.

$s_{P<.05}$.

Table 4. Relationship Between Components of Psychosocial Adjustment in the Diabetes Care Profile and Contingency Contracting for Adherence to Nutrition Recommendations

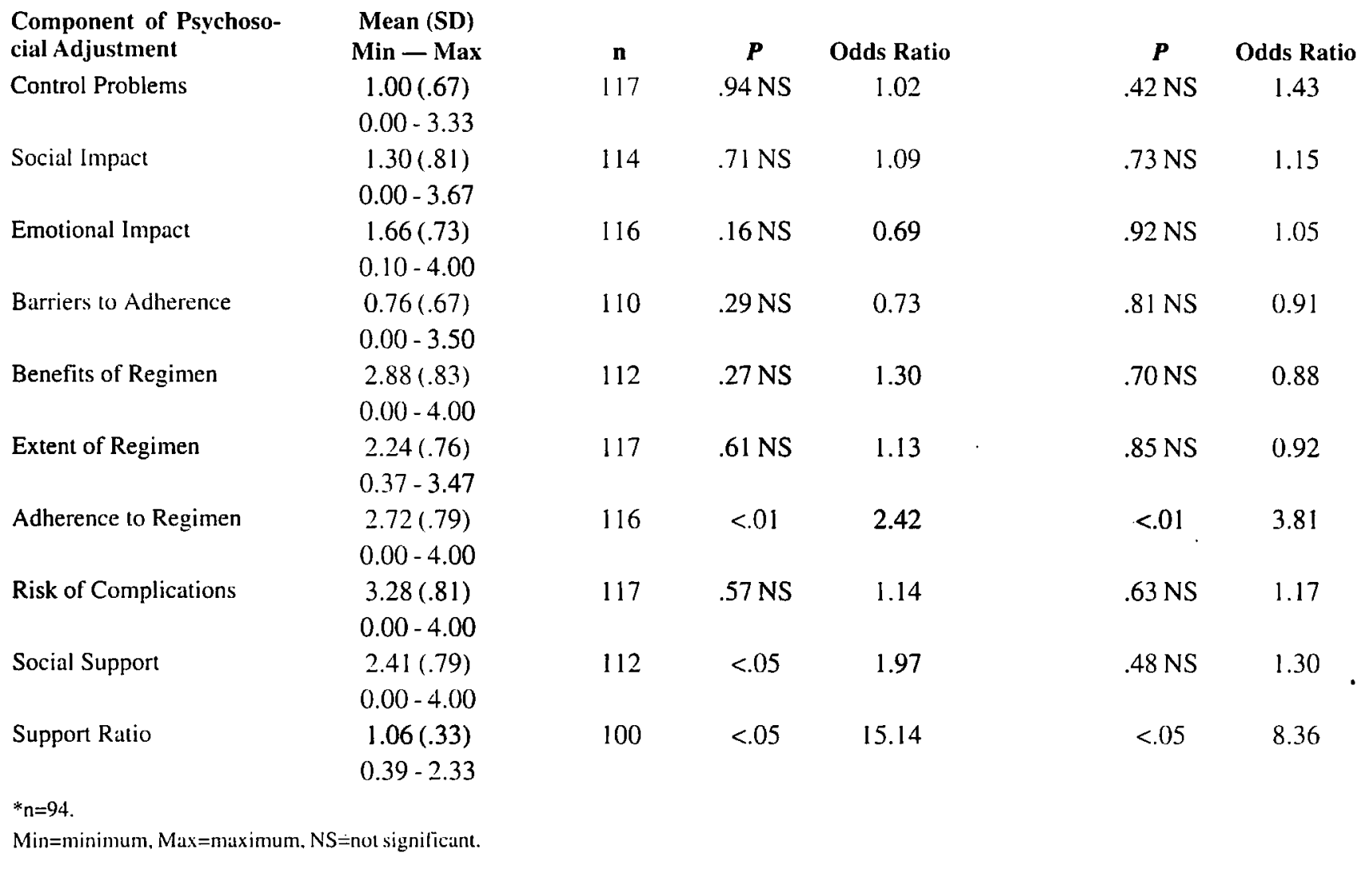


contracting for adherence to nutrition recommendations. Means, standard deviations, and ranges for the DCP predictors are shown in Table 4. Analyses of support ratio indicate that on this interval level measure $44 \%$ received less support than desired (support ratio $<1.0$ ), 19\% received support that matched desired support (support ratio=1.0), and 37\% received more support than desired (support ratio $>1.0$ ).

Multivariate Analyses The relationships between the DCP predictors and contingency contracting for adherence to nutrition recommendations are described in Table 4 . Bivariate relationships between each DCP predictor and contingency contracting for adherence to nutrition recommendations are identified on the left side of the table with $P$ values derived from the $W$ ald test in bivariate logistic regression and the odds ratios. Multivariate relationships of the DCP predictors to contingency contracting for adherence to nutrition recommendations are identified on the right side of the table with $P$ values from Wald tests in multiple logistic regression predicting adherence to nutrition recommendations from all 10 predictors and the odds ratios. In this part of the table the relationships are characterized when controlling for all of the other predictors.

Contingency contracting for adherence to nutrition recommendations was associated with statistically significant relationships with adherence to the regimen, social support, and support ratio (Table 4). When controlling for the other DCP predictors, social support no longer was significant in the multivariate analysis, whereas both the bivariate and multivariate analyses showed relationships with regimen adherence and support ratio. Only weak multicollinearity existed between social support and support ratio $(r=.26$, $P<.05$ ). Thus, multicollinearity does not explain the nonsignificance of social support. The odds ratio for regimen adherence was greater than 2 . which was statistically significant at the .01 level in both analyses. The odds ratio for support ratio was greater than 8 , which was statistically significant at the .05 level in both analyses. Subjects with higher adherence to the regimen and higher support ratio (received more social support than desired) were more likely than subjects with lower regimen adherence and lower support ratio (received less social support than desired) to have low contingency contracting for adherence to nutrition recommendations (the indicator group). Using the formula provided by Agresti, ${ }^{46}$ the amount of variance in contingency contracting for adherence to nutrition recommendations explained by the multivariate logistic regression was $17.4 \%$. The overall multivariate logistic regression for predicting contingency contracting for adherence to nutrition recommendations was significant (model chi-square $=22.21, P<.05$; goodness of fit $=92.70, P=.22 \mathrm{NS}$ ), with $71.3 \%$ of the subjects correctly classified into high and low contingency contracting for adherence to nutrition recommendations.

Additional Analyses Chi-square analyses were performed between the significant independent DCP predictors and contingency contracting for adherence to nutrition recommendations to describe the directions and other features of the relationships. The percentages of subjects in the cells showed that the association of regimen adherence and low contingency contracting for adherence to nutrition recommendations occurred between those in the lower two quartiles on regimen adherence (each cell is about $39 \%$ low adherence to nutrition recommendations) and those in the upper two quartiles (each cell is about $75 \%$; chisquare $=15.34, d f=3, P<.(01$, Cramer's V=.37, $\mathrm{n}=116)$. Using the percentages of subjects in the cells, the association of support ratio and low contingency contracting for adherence to nutrition recommendations was found to occur between those in the lower three quartiles on support ratio (each cell $<54 \%$ low adherence to nutrition recommendations) and those in the upper quartile (each cell is $84 \%$ : chisquare $=11.54, d f=3, P<.01$. Cramer's V $=.34, n=100$ ).

To rule out alternative determinants of contingency contracting for adherence to nutrition recommendations, analyses were conducted that showed that treatment time was not related to adherence to nutrition recommendations. In addition, no differences were found in adherence to nutrition recommendations among contingency contracting groups.

\section{Discussion}

Two components of psychosocial adjustment in the DCP were found to be significant independent predictors of adherence to nutrition recommendations during a behavioral intervention of contingency contracting. Patients with NIDDM who perceived higher regimen adherence and higher support ratio (received more diabetes-specific social support than desired) were significantly less likely to engage in contingency contracting for adherence to nutrition recommendations. Among this group of patients with NIDDM. those who perceived themselves as highly adherent to the regimen did not complete as many contingency contracts for adherence to nutrition recommendations as those who believed that they were less adherent to the regimen. One possible explanation is that because of the importance of adherence to nutrition recommendations in NIDDM and the emphasis placed on adherence by diabetes educators, the self-rating of regimen adherence may largely reflect patients' beliefs about personal nutrition behaviors. Thus, patients who believe that they already are adherent to their treatment program. of which a major component is nutrition. are less likely to make additional changes in nutrition behaviors. Low levels of contingency contracting for adherence to nutrition recommendations by patients who believe they already are adherent are appropriate if their self-evaluation is accurate, but not otherwise. Thus, if patients indicate high regimen adherence on this component of psychosocial adjustment in the DCP, it may be desirable to further assess their adherence to the nutrition regimen to insure that their self-evaluation is correct and to guide them to a more accurate self-evaluation as needed.

Social factors have been implicated as important factors of adherence to medical recommendations. Support from family members and friends appears to play an important role in patients initiating and maintaining adherence behaviors. However, the relationship between social support and adherence is not always clear-cut. It is unclear how different types of support and network composition may affect diabetes adherence. ${ }^{47}$ In this study, receiving more social support than desired negatively affected the likelihood of engaging in contingency contracting for adherence to nutrition recommendations. One possible hypothesis is that too much social 
support may manifest itself as nagging or be viewed as harassment by the recipient. Therefore, patients who perceive misguided help from family and friends during their attempts to make nutrition behavior changes may be less likely to choose these behaviors in order to avoid creating a negative situation for themselves. ${ }^{48}$ Indeed, Schafer et al ${ }^{18}$ reported that the presence of negative or nonsupportive interactions with family members specific to the diabetes regimen was related to lower levels of regimen adherence for adults. Assisting patients in determining the amount and types of social support that would be beneficial appears to be an important part of the assessment process by diabetes educators. This assessment could be facilitated by discussion of a patient's responses to items in the support ratio component of psychosocial adjustment in the DCP. In addition, communication skills, assertiveness strategies, problem-solving techniques, and self-efficacy enhancement to request the type of support desired should be included in selfmanagement training and contingency contracting for patients with NIDDM.

Nutrition and exercise have been found to be the most difficult aspects of the diabetes self-care regimen for patients to manage. ${ }^{49.50}$ Because behaviors such as these are deeply rooted in culture and lifestyle, patients could benefit from the use of behavioral strategies that go beyond traditional diabetes patient education. ${ }^{51}$ Both diabetes educators and patients need to focus specific attention on nutrition and exercise behaviors because of the impact of these behaviors on longterm outcomes for patients with NIDDM. Therefore, these findings have important clinical implications for diabetes educators who provide care for patients with NIDDM. Perceived regimen adherence and support ratio appear to significantly influence the likelihood that patients can change their nutrition behaviors. Thus, assessment of these perceptions as part of the educational process provides an important guide for the behavior change program.

\section{References}

1. Fran\% MJ. Horton ES. Bantle JP. et al. Technical review: nutrition principles for the management of diabetes and related complicalions. Diabeles Carc 1994:17:4901-518.

2. American Diabetes Association. Position statement: nutrition recommendation and principles for people with diabetes mellitus. Diathetes Care 1994,17:519-22

3. Bradley $\mathrm{C}$. Contributions of psychology to diabetes management. $\mathrm{Br} J$ Clin Psychol 1994;33(part 1): 1 1-21.

4. Cox DJ, Gonder-Frederick L. Major developments in behiavioral diabetes research. J Consult Clin Psychol 1992:60:628-38.

5. Fisher EB Jr, Delamuter AM, Bertelson AD. Kirkley BG. Psychologicall factors in diabetes and its treatment. J Consult Clin Psychol 1982:50: 993-1003.

6. Becker MH. Maiman LA. Sociobehavioral determinants of compliance with health and medical care recommendations. Med Care 1975;13:10-24

7. Rosenstock IM. Historical origins of the health belief model. Health Educ Monogr 1974;2:328-35.

8. Hampson SE, Glasgow RE, Toobert DJ. Personal models of diabetes and their relations to selfcare activities. Health Psychol 1990:9:632-46.
9. Cerkoney KAB. Hart LK. The relationship between the health belief model and compliance of persons with diabetes mellitus. Diabetes Care 1980:3:594-98.

10. Harris R. Linn MW. Health beliefs, compliance, and control of diabetes mellitus. South Med J 1985;78:162-66

11. Alogna M. Perception of severity of disease and health locus of control in compliant and noncompliant diabetic patients. Diabetes Care 1980;3:533-34.

12. Brownlec-Duffeck M, Peterson L. Simonds JF, Goldstein D, Kilo C, Hoetie $S$. The role of health beliefs in the regimen adherence and metabolic control of adolescents and adults with diabetes mellitus. J Consult Clin Psychol 1987:55:139-41

13. Glasgow RE. McCaul KD. Schafer LC. Barriers to regimen adherence among persons with insulin-dependent diabetes. J Behav Med 1986;9:65-77.

14. Clitsgow RE. Tootert DJ, Ridale M, Donnelly J, Mitchell DL, Calder D. Diabeles-specific social leaming variables and self-care behaviors among persons with type II diabetes. Health Psychol 1989:8:285-303.

15. Irvine AA, Saunders JT, Blank MB, Carter WR. Validation of scale measuring environmental barriers to diabetes-regimen adherence. Diabetes Care 1990:13:705-11

16. Wilson W, Ary DV, Biglan A, Glasgow RE. Toober DJ. Campbell DR. Psychosocial predictors of self-cure hehaviors (compliance) and glycemic control in non-insulin-dependent diabetes mellitus. Diabetes Care 1986:9:61+-22

17. Glasgow RE. Toober DJ. Social environment and regimen adherence among type II diabetic palients. Diabetes Care 1988:1 1:377-86.

18. Schaler LC. McCaul KD. Glasgow RE. Supportive and nonsupportive fumily behaviors: relationships to adherence and metabolic control in persons with type I diabetes. Diabetes Care 1986:9:179-85

19. Schlenk EA, Hart LK. Relationship between health locus of control, health value. and social support and compliance of persons with diabetes mellitus. Diabetes Care 1984;7:566-74.

20. Wysocki T. Hough BS, Ward KM. Green LB. Diabetes mellitus in the transition to adulthood: adjustment, self-care, and health status. J Dev Behav Pedialr 1992:13:194-201.

21. Brow'n SA. Hedges LV. Predicting metabolic control in diabetes: a pilot study using meta-analysis to estimate a linear model. Nurs Res 1994:43: 3 2. $2-68$

22. Hess GE, Davis WK, Harrison RV. A diabetes psychosocial profile. Diahetes Educ 1986:12:135-40.

23. Davis WK, Hess GE. Harrison RV, Hiss RG. Psychosocial adjustment to and control of diabetes mellitus: differences by disease type and treatment. Health Psychol 1987:6:1-14

24. Davis WK, Hess GE. Hiss RG. Psychosocial correlates of survival in diabetes. Diabeles Care 1988;11:538-45.

25. Steckel SB. Patient contracting. Norwalk, Conn: Appleton-CerturyCrolts, 1982

26. Weddington WW Jr. Blindt K. Behavioral medicine: a new development. Hosp Community Psychiatry 1983:34:702-8.

27. Brigham T. Self-management: a radical behavioral perspective. In: Karoly $\mathrm{P}, \mathrm{Kamfer} \mathrm{FH}$, eds. Self-management and behavior change: from theory to practice. New York: Pergamon Press, 1982:32-59.

28. Buthm S. Patient contracting. In: Bulechek GM, McCloskey JC, eds. Nursing interventions: essential nursing treatments. 2nd ed. Philadelphia: WB Saunders, 1992:425-33. 
29. US Department of Health and Human Services. Public Health Service. The 1990 health objectives for the nation: a midcourse review. Rnckville, Md: US Deparment of Health and Human Services. 1986.

30. Berk RA. Importance of expert judgment in content-relatted validity evidence. West J Nurs Res 1990:12:659-71.

31. Davis LL. Instrument review: getting the most from a panel of experts. Appl Nurs Res 1992;5:194-97.

32. Lynn MR. Determination and quantification of content validity. Nurs Res 1986;35:382-85.

33. Nunnally JC. Psychometric theory. 2nd ed. New York: McGraw-Hill. 1978.

34. Slocumb EM. Cole FL. A practical approach to content validation. Appl Nurs Res 1991:4:192-95.

35. Wiltz CF. Strickland OL, Lenz ER. Measurement in nursing research. 2nd ed. Philadelphia: FA Davis. 1991

36. Ryan JW, Phillips CY. Prescot PA. Interrater reliability: the underdeveloped role of rater training. Appl Nurs Res 1988: $1: 1+8-50$.

37. Topf $M$. Interrater reliability decline under covert assessment. Nurs Res 1988:37:47-49.

38. Washington CC, Moss M. Pragnatic aspects of estahlishing interrater reliability in research. Nurs Res 1988:37:19()-91.

39. Brennan PF. Hays BJ. The kappa statistic for establishing interrater reliability in the secondary analysis of qualitative clinical dati. Res Nurs Health 1992:15:153-58.

40. Garvin BJ, Kennedy CW. Cissna KN. Reliability in caltegory coding sys1ems. Nurs Res 1988:37:52-55.
41. Goodwin LD, Prescott PA. Issues and approaches to estimating interrater reliability in nursing research. Res Nurs Health 1981;4:323-37.

42. Lynn MA. Reliability estimates: use and disuse. Nurs Res 1985:34: $254-56$.

43. Topf $M$. Three estimates of interrater reliability for nominal data. Nurs Res 1986,35:253-55.

44. Boehm S. Schlenk EA. Raleigh E. Ronis D. Behavioral analysis and behavioral strategies 10 improve self-management in type II diabetes. Clin Nurs Res 1993:2:327-44.

45. Hirris RJ. A primer of multivariate statistics. 2nd ed. Orlando. Fla: Academic Press, 1985.

46. Agresti A. Categorical data analysis. New York: Wiley \& Sons. 1990.

47. Anderson LA. Health-care communication and selected psychosocial correlates of adherence in diabetes management. Diabetes Care 1990; 13(suppl 2):66-76.

48. Glasgow RE, Toober DJ, Hampson SE, Wilson W. Behavioral research on diabetes at the Oregon Research Institute. Ann Behav Med 1995; 17:32-40.

49. Glasgow RE, Toobert DJ, Hampson SE, Brown JE, Lewinsohn PM. Donnelly J. Improving self-care among older patients with type Il diabetes: the "Sixty Something..." study. Patient Educ Couns 1992;19:61-74.

50). Lockwood D, Frey ML. Gladish NA, Hiss RG. The biggest problem in diabetes. Diabetes Educ 1986:12(1):30-33.

5I. Ruhin RR, Peyrot M. Saudek CD. Differential effect of diabetes education on sell-regulation and lifestyle behaviors. Diabetes Care 1991;14: 335-38. 